\title{
Wissen ist Macht
}

\section{Erhard Taverna}

Dr. med., Mitglied der Redaktion
Das geflügelte Wort geht auf den englischen Aufklärer Francis Bacon (1561-1626) zurück. Die Naturwissenschaft solle den Menschen in ein höheres Dasein überführen. Auch Bertolt Brechts Galilei sieht das einzige Ziel der Wissenschaft darin, die Mühseligkeit der menschlichen Existenz zu erleichtern. Als Bühnenfigur beklagt er seinen Rückzieher vor der Inquisition, denn als Märtyrer wäre er ein Vorbild gewesen. «Wie es nun steht, ist das Höchste, was man erhoffen kann, ein Geschlecht erfinderischer Zwerge, die für alles gemietet werden können.»

Wie steht es um Galileis Nachfahren, die «erfinderischen Zwerge?» Siebzig Jahre nach der Zerstörung von Hiroshima und Nagasaki rückten einmal mehr das Megaprojekt Manhattan und die Schicksale der führenden Forscher in den Fokus der Medien. Nach beiden Atombombenabwürfen sprach das Weisse Haus von der historisch grössten Errungenschaft der organisierten Wissenschaft.

\section{In jedem von uns steckt die Doppelnatur von Dr. Jekyll und Mr. Hyde.}

Weit weniger mediale Beachtung fand 2015 das Schicksal der deutschen Gegenspieler. Sie alle, auch Heisenberg, erklärten sich 1939 bereit, das waffentechnisch nutzbare Uranprojekt voranzureiben. Zehn Kernphysiker, darunter auch Hahn und Weizsäcker, wurden im Juli 1945 festgenommen und sechs Monate im abgelegenen Landhaus Farm Hall in England, unter komfortablen Bedingungen, interniert. Was sie nicht wussten war, dass sie in allen Räumen, rund um die Uhr, abgehört wurden. 1993 wurden die Protokolle der monatelangen Lauschaktion veröffentlicht. In seinem Buch Die Nacht der Physiker schildert Richard von Schirach eine Geschichte von Verfehlungen, Loyalitäten, Dünkel, Illusionen, Bekenntnissen, Zusammenbrüchen und Selbsttäuschungen [1]. Die aufgezeichneten Szenen erinnern auf beklemmende Weise an Dürrenmatts Die Physiker. Möbius, die geniale Hauptfigur, täuscht Wahnsinn vor, um die Welt vor seinen Entdeckungen zu bewahren. Doch die Leiterin der Anstalt, die Irrenärztin Dr. Mathilde Zahrndt, hat längst alle Unterlagen kopiert. Sie gründet einen Weltkonzern und die schlimmstmögliche Wendung nimmt ihren Lauf.

Macht und Ohnmacht des Forschers sind ein Urthema der Literatur. Die Zuspitzung des Dramatikers zerstört die illusorische Vorstellung vom stets verantwortungsbewussten Forscher, der alle Folgen seines Handelns selbst bestimmt. In der UdSSR der 70er Jahre haben in geheimen Städten über eine Million Menschen für die Nuklearphysik gearbeitet. Heute wird in Deutschland um Hochschulen als entmilitarisierte Zonen gestritten. Sogenannte Zivilklauseln sollen die Universitäten dazu verpflichten, weder Forschung noch Lehre für militärische Zwecke zu akzeptieren. In Zeiten dringend benötigter Drittmittel keine leichte Aufgabe, zumal DualUse-Produkte zivil und militärisch verwendet werden. Die angebliche Verantwortung der Wissenschaft führt in ein unlösbares Dilemma. Seit Edward Snowden das Ausmass der globalen Bespitzelung öffentlich machte, ist jede Informationstechnologie unter Verdacht geraten. Snowden hätte, gut bezahlt in seinem Haus auf Hawaii, weiter Software für Überwachungsprogramme wie Prism und Tempora entwickeln können. Statt als Vorbild im Sinne Galileis geehrt zu werden, wird er als Verräter und Spion gejagt. Solscheniyzin hat in seinem Roman Der erste Kreis der Hölle die Zustände in einem stalinistischen Arbeitslager beschrieben. Schon damals ging es um die Identifikation von Stimmen am Telefon. Heute bezahlt die NSA deutsche Forschungsprogramme zur digitalen Stimmenanalyse und Spracherkennung. Die Universität Karlsruhe hat wesentlich zum Programm Total Information Awareness, der Grundlage für das Prism-Programm zur Massendatenauswertung, beigetragen. Offiziell beendet, wird es aus einem Schattenhaushalt amerikanischer Geheimdienst- und Militärprogramme mit zusätzlichen deutschen Steuergeldern weiter finanziert. Der zuständige Professor bestreitet die Brisanz seiner Forschung: «Sie können Strassen bauen und dann fahren Autos darüber und irgendwann auch Panzer. Sie können nicht eine Welt kreieren, von der Sie das Wissen, das die Wissenschaft kreiert, völlig trennen können.» Natürlich hat er auf seine zynische Art Recht. Wissen ist Macht und Macht ist Wissen. Bühnendramen zum Thema haben eine Gerichtsstruktur. Sie erheben Einspruch, wenn auch zunehmend desillusioniert, gegen die bequeme These der Sachzwänge. In jedem von uns steckt die Doppelnatur von Dr. Jekyll und Mr. Hyde.

\section{Literatur}

1 von Schirach R. Die Nacht der Physiker. Reinbek: Rowohlt Taschenbuch Verlag; 2014. 